\title{
Prophylaxis for deep venous thrombosis in patients with craniotomies: a review
}

\author{
Shabbar F. Danish, M.D., Mark G. Burnett, M.D., and Sherman C. Stein, M.D. \\ Department of Neurosurgery, The Hospital of the University of Pennsylvania, Philadelphia, \\ Pennsylvania
}

\begin{abstract}
Deep venous thrombosis (DVT) remains a source of significant morbidity and mortality in patients who undergo craniotomy procedures. Despite several studies in which the safety and efficacy of various prophylactic strategies were examined, there is still no consensus among clinicians. In this paper the authors review the literature with regard to epidemiological and pathophysiological features, screening methods, and prophylactic measures for DVT.
\end{abstract}

\section{KEY WORDS • craniotomy - deep venous thrombosis • heparin • neurosurgery • pulmonary embolism}

Deep venous thrombosis is perhaps the single most significant preventable cause of morbidity and mortality in the neurosurgical patient population nowadays. Although the lack of a standard definition for DVT (for example, clinically silent or symptomatic) and differing screening methods make interpretation of the current research findings difficult, average estimates place the incidence of DVT at approximately $25 \%$ in patients who undergo neurosurgery. ${ }^{2}$ In isolation DVT is not a lifethreatening disorder, but in 1.5 to $5 \%$ of patients with this condition PE will develop, and PE is fatal in as many as $50 \%$ of these cases.

Prevention protocols for DVT have been widely discussed in the neurosurgical literature, but disagreement remains about the safety and effectiveness of these strategies. Many neurosurgeons fear the use of anticoagulating agents following intracranial surgery because of the risk of intracerebral hemorrhage. Others believe that mechanical compression is not effective enough as the sole preventive therapy. A lack of standardized research methods is partly to blame for the persisting debate. In this brief review, we discuss the pathophysiological features of DVT and summarize findings in the current literature with regard to the diagnosis, screening, and prevention of this perioperative killer.

\section{EPIDEMIOLOGICAL FINDINGS}

Although there is a great deal of variation in the statistics with regard to the overall incidence of DVT, all of the reported figures are quite high. In 1984 Coon $^{20}$ estimated that more than 250,000 symptomatic DVTs are diagnosed

Abbreviations used in this paper: DVT = deep venous thrombosis; ICH = intracranial hemorrhage; $\mathrm{PE}=$ pulmonary embolism. in the US each year. Because symptomatic thromboses represent only a portion of the total incidence of DVT, Coon used the incidence of PE as a marker for DVT and extrapolated back to determine that the overall incidence of DVT is between 1.8 and 3 million cases per year. In a more recent study, researchers found a similar number of symptomatic DVTs and calculated that DVT-related PE is the direct cause of more than 100,000 deaths annually in hospitals in the US. ${ }^{3}$

It is widely accepted that neurosurgical patients are at high risk for DVT when compared with other surgical and medical patient populations. The mean incidence of DVT in neurosurgical reports approaches $25 \%$, depending on the study's methodology. ${ }^{4}$ The incidence of PE is thought to be between 1.5 and $3 \%, 4,74$ with a mortality rate between 9 and 50\%. ${ }^{2}$ Factors that place neurosurgical patients at high risk for DVT can be separated into clinical risk factors, which are related to the patient's physical status, and biological risk factors, which are unique to the underlying neuropathological features.

\section{Clinical Risk Factors}

General clinical risk factors for the development of DVT and PE include older age, heart failure, previous episodes of DVT, obesity, and malignancy, and these factors are present in much of the neurosurgical patient population. ${ }^{2}$ In addition to these general factors, a number of clinical risk factors specific to the neurosurgical population have been identified. In a study of 443 patients undergoing craniotomy, Macdonald, et al., ${ }^{41}$ observed that the factors that increased the risk of development of DVT included the presence of preoperative leg weakness, longer pre- and postoperative intensive care unit stays, prolonged hospital stay, prolonged recovery room time, and delayed initiation of mobility and activity. 
Other investigators have confirmed these factors, emphasizing the importance of extremity paresis and also the significant increase in DVT risk following craniotomy as opposed to spinal surgery (Table 1). ${ }^{8,51}$ Bostrom, et al., ${ }^{8}$ examined the influence of both paresis and surgery site on the incidence of DVT and found that DVT occurred in $14 \%$ of patients without paresis who underwent craniotomy and in none of the patients without paresis who underwent spinal surgery. In patients with lower-limb paresis postsurgery, the incidence of DVT was $57 \%$ after intracranial surgery and $14 \%$ after spinal surgery. The neurosurgical literature has even mentioned factors such as race as having an effect on the incidence of DVT. In one screening study, researchers found that the incidence of DVT was $4 \%$ in Chinese patients who underwent craniotomy, and the incidence in a non-Chinese matched population was 10 to $15 \%$. The authors hypothesized that these findings may be due to a difference in the prevalence of activated protein $\mathrm{C}$ resistance between the two populations. ${ }^{64}$

It should be noted that our review is focused on perioperative DVT and therefore a discussion of patient populations such as those with stroke and spinal cord injury is not included. The nature and chronicity of these conditions places patients at extraordinarily high risk for DVT; the rate is as high as $76 \%$ in patients with stroke and $100 \%$ in patients with spinal cord injury according to follow-up studies. $^{32,46,60}$

\section{Biological Risk Factors}

There has been an attempt to elucidate the biological mechanisms that place craniotomy patients at high risk for DVT; however, the specific mechanisms have yet to be demonstrated. Most of the research focuses on patients with brain tumors, a subpopulation that has been found to have perhaps the greatest risk of DVT of all patients who undergo neurosurgery.

Coagulation abnormalities have been identified that are believed to play a role in DVT. These include elevations in fibrinopeptide $\mathrm{A}$ and fibrinogen fragment $\mathrm{B} \beta 15-42$; decreased activated partial thromboplastin time and increased fibrinopeptide A levels; and subclinical disseminated intravascular coagulation. ${ }^{32}$ Tissues obtained in patients with intracranial tumors who experienced throm-

TABLE 1

Risk factors for thromboembolism

in patients who undergo craniotomy

\begin{tabular}{ll}
\hline \multicolumn{1}{c}{ General } & \multicolumn{1}{c}{ Specific } \\
\hline $\begin{array}{l}\text { age }>60 \text { yrs } \\
\text { history of DVT } \\
\text { duration of op procedure } \\
\text { prolonged immobilization } \\
\text { central line }\end{array}$ & $\begin{array}{c}\text { supratentorial/suprasellar } \\
\text { location } \\
\text { tumor histological type } \\
\text { infection } \\
\text { pbesity }\end{array}$ \\
use of oral contraceptive pills \\
heart failure \\
pregnancy \\
deficiency \\
antithrombin III \\
protein C or S
\end{tabular}

boembolic events have been shown to have an imbalance of plasminogen activator and inhibitor systems. ${ }^{57}$ More specifically, brain tumors have been found to inhibit plasmin, enhance release of thromboplastin, and increase procoagulant and platelet aggregatory activity. ${ }^{15}$ In a study of 114 patients with brain tumors, Sawaya, et al. ${ }^{56}$ found that total fibrinolytic activity was reduced in patients with malignant brain tumors. Plasminogen and plasmin inhibitor levels did not show significant changes, but tissue plasminogen activator was low and plasminogen activator inhibitor-1 levels were high in a large proportion of patients.

The overall risk that a patient with a brain tumor will display a DVT on follow-up studies is reported to be between 22 and 45\%.55,59,61,66 Clearly, as mentioned in the previous section, clinical factors specific to patients with tumors, such as supratentorial and suprasellar locations, increase risk. ${ }^{19}$ In addition to these clinical factors, there is evidence that biological factors such as tumor histological features may define different levels of DVT risk. Sawaya, et al. ${ }^{58}$ found that the incidence of DVT in patients with meningiomas, malignant glioma, and metastatic disease was 72,60 , and $20 \%$, respectively. In studies by Missori, et al. ${ }^{44}$ and Levi, et al., ${ }^{39}$ these investigators also noted that meningiomas seem to carry the highest risk of DVT of all intracranial tumors, especially when the lesions are in close contact with a venous sinus.

Unfortunately, data such as these are purely observational, and to date there is little in the way of a mechanistic explanation for these pathological associations. Perhaps the greatest contributor to the reported variation of DVT risk among patients with brain tumors is the degree of clinical attentiveness. The incidence of clinical DVT appears to be much higher in series in which the focus was thromboembolic complications of tumors; in more general brain tumor series much lower DVT rates are reported, as is evident from Table 2.

Chemotherapeutic agents used to combat brain tumors have also been linked to increased DVT risk. Specifically,

TABLE 2

Literature review of risk of perioperative thromboembolism without prophylaxis after craniotomy for brain tumor*

\begin{tabular}{|c|c|c|c|c|c|}
\hline \multirow[b]{2}{*}{ Authors \& Year } & \multirow[b]{2}{*}{$\begin{array}{l}\text { No. of } \\
\text { Patients }\end{array}$} & \multirow{2}{*}{$\begin{array}{c}\text { No. w/ } \\
\text { Clinical } \\
\text { DVT (\%) }\end{array}$} & \multicolumn{2}{|c|}{ Clinical PE } & \multirow{2}{*}{$\begin{array}{c}\text { Brain } \\
\text { Tumor } \\
\text { Type }\end{array}$} \\
\hline & & & No. $(\%)$ & $\begin{array}{l}\text { No. of } \\
\text { Deaths }\end{array}$ & \\
\hline $\begin{array}{l}\text { Tomita \& Raimondi, } \\
1981\end{array}$ & 80 & NR & $3(3.8)$ & 0 & NR \\
\hline Ruff \& Posner, 1983 & 264 & $66(25.0)$ & NR & NR & glioma \\
\hline Fadul, et al., 1988 & 213 & $5(2.3)$ & $3(1.4)$ & 0 & glioma \\
\hline Cheruku, et al., 1991 & 77 & $0(0)$ & $0(0)$ & 0 & $\begin{array}{l}\text { malignant } \\
\text { glioma }\end{array}$ \\
\hline $\begin{array}{l}\text { Constantini, et al., } \\
1991\end{array}$ & 633 & $23(3.6)$ & $19(3.0)$ & 7 & all \\
\hline Levi, et al., 1991 & 1703 & $17(1.0)$ & $10(0.6)$ & 0 & all \\
\hline Wilson, 1993 & 1771 & $30(1.7)$ & $17(1.0)$ & 8 & all \\
\hline $\begin{array}{c}\text { Cabantog \& Bernstein, } \\
1994\end{array}$ & 207 & $5(2.4)$ & $1(0.5)$ & 1 & all \\
\hline total & 4948 & $146 / 4868$ & $53 / 4684$ & $16 / 53$ & \\
\hline weighted means & & $3.0 \%$ & $1.1 \%$ & $30.2 \%$ & \\
\hline
\end{tabular}

$* \mathrm{NR}=$ not reported. 
the use chemotherapy regimens that include either 1,3bis(2-chloroethyl)-1-nitrosourea or cisplatin increase the risk of DVT and PE. ${ }^{45}$

\section{Screening Methods for DVT}

One reason the published incidences vary as much as they do could be the inconsistencies in study methodologies rather than true biological variation. Authors of various studies have chosen different definitions of what they believe to be a clinically relevant DVT, and they have also used screening methods with significantly different sensitivities.

Clinically, calf-vein thrombi are relatively benign unless they extend into the proximal veins. Most proximal-vein DVTs do not propagate out of the calf veins but form de novo in the major axial venous segments. Isolated calf-vein thrombi result in pulmonary emboli in less than $1 \%$ of cases, whereas thrombi in the proximal veins result in pulmonary emboli 40 to $50 \%$ of the time. ${ }^{54,70} \mathrm{Al}$ though most DVTs arise in the infrapopliteal veins, the major sources of emboli are proximal DVTs. Deep venous thromboses in the lower extremities are the source of $90 \%$ of pulmonary emboli, the remainder arise mostly from DVTs in the pelvis. ${ }^{37}$ Nevertheless, there are no studies in which the incidence of DVT in the upper extremities and the risk of PE in this patient population have been examined. Missori, et al. ${ }^{44}$ found that in $88 \%$ of patients with pulmonary emboli the source lay in the proximal veins. Therefore, it may not be clinically necessary or efficient to scan routinely for calf-vein DVTs.

The presence of clinical symptoms of DVT is as unreliable a marker for this disease as their absence. The traditional clinical features, such as a swollen, tender, warm calf; venous dilation; or a positive Homan sign, are associated with proven DVT in only 20 to $50 \%$ of patients. Conversely, 50 to $60 \%$ of patients with DVT will not have these symptoms, a finding supported by the substantial number of those with PE who present with no clinical evidence of DVT. ${ }^{31}$

The ${ }^{125}$ I-Labeled Fibrinogen Test. Several DVT screening tests are available. One of these is the ${ }^{125}$ I-labeled fibrinogen test, in which radiolabeled fibrinogen is injected intravenously, where it becomes incorporated into any developing thrombus and is visible on scans. Using the ${ }^{125} \mathrm{I}-$ labeled fibrinogen test to evaluate DVT reveals an incidence of 29 to $43 \%$, with 10 to $17 \%$ of these thrombi progressing to become clinically evident. There have been conflicting reports about its clinical usefulness, with some authorities stating that the test is too sensitive and that it detects many small DVTs that resolve spontaneously. ${ }^{19,66}$ Levi, et al. ${ }^{39}$ reported that the technique had a positive predictive value of only $66 \%$, with an overall accuracy of $70 \%$. In one study a false-positive rate of $24 \%$ was reported when the findings on ${ }^{125}$ I-labeled fibrinogen scans were confirmed by other methods. ${ }^{61}$ In addition, radiolabeled fibrinogen scanning was found to be inaccurate for detection of clots originating in the pelvis and thigh, which are thought to be the most life-threatening types.

Impedance Plethysmography. A second method for diagnosing DVT is impedance plethysmography; this is the indirect assessment of blood-volume changes in any part of the body by measurement of the blood's electrical impedance. Because blood is a good conductor of electricity, blood-volume changes in any part of the body are reflected inversely in the electrical impedance of the particular body segment. A continuous uniform flow of blood produces no significant change in the electrical impedance of the body segment, whereas pulsatile blood-volume changes are recorded as electrical impedance changes over time. With this technique practitioners can monitor the decreasing electrical impedance that blood produces as it leaves the calf veins through the proximal leg veins after relaxation of a pneumatic tourniquet. With obstruction of the proximal veins by a thrombus, the egress of blood from the calf and therefore the results of impedance plethysmography are abnormal..$^{33}$ One of the advantages of this modality is that it is relatively easy to perform and there is very little inter- or intraobserver variation. Moreover, the risk of PE in patients with negative results on serial impedance plethysmography evaluations is less than $1 \%$. Because false-negative findings can occur as the result of nonocclusive proximal DVT and in patients with well-developed collateral vessels, a negative finding on impedance plethysmography must be repeated over at least a 2-week period. ${ }^{31}$

Doppler Ultrasonography. Doppler ultrasonography is the third major diagnostic test for DVT. This test is based on the same principle as impedance plethysmography; it detects the abnormal egress of blood from the calf when a thrombus is present. Doppler ultrasonography is noninvasive and painless. The addition of real-time B-mode imaging allows the venous anatomy, clot structure, and blood flow to be visualized. The accuracy of Doppler scanning in the diagnosis of DVT has been well documented, especially for proximal DVT, for which a sensitivity and specificity of more than $90 \%$ has been achieved. ${ }^{64,71}$ Some advantages over impedance plethysmography include the ability to perform the test in patients who are immobilized and in those who have lower leg casts or amputations. In addition, ultrasonography is more readily available in most treatment centers. The major disadvantage is that data interpretation can be highly subjective and requires a high level of skill, which is not the case with impedance plethysmography. ${ }^{33}$

Venography. Although it is invasive, venography remains the definitive diagnostic test for DVT. Using fluoroscopy and a contrast dye, venography provides a dynamic and detailed image of the leg veins. It is extremely sensitive in identifying the location, extent, and degree of attachment of a clot. Rossi, et al., ${ }^{53}$ state that venography remains the only reliable diagnostic method for DVT detection in patients who are asymptomatic postoperatively, but that it is not a practical screening test. Venography exposes the patient to radiation, it is painful, and it takes approximately 30 to 45 minutes to perform. The test also carries the risk of allergic reactions and renal dysfunction, and may actually produce a new DVT in approximately $1 \%$ of cases. ${ }^{64}$ Additionally, good interobserver agreement has been difficult to achieve. ${ }^{53}$

\section{Strategies for DVT Prophylaxis}

The methods used for pericraniotomy DVT prophylaxis are mechanical, pharmacological, or a combination of both. 


\section{S. F. Danish, M. G. Burnett, and S. C. Stein}

Mechanical. These techniques include the use of graduated compression stockings, electrical stimulation of the calf muscles, intermittent external pneumatic calf compression, and rotating tables. The main advantages of mechanical prophylaxis are that there is minimal risk associated with them, and they are relatively inexpensive and simple to use. ${ }^{21}$

Both local and systemic factors appear to be involved in the success of mechanical prophylaxis. Elastic support of 16 to $20 \mathrm{~mm} \mathrm{Hg}$ decreases venous stasis and increases venous return. Leg wrappings and stockings with no pressure gradient are ineffective in the prevention of DVT. ${ }^{10}$ The period of "fibrinolytic shutdown" after surgery appears to be reversed with intermittent calf compression. ${ }^{11}$ In one comparison of mechanical devices, Vanek ${ }^{67}$ suggested that pneumatic compression was superior to stockings in preventing DVT but not PE, but admitted that the data were "sparse and conflicting."

Pharmacological. Although several medications, including aspirin, unfractionated heparin, low-molecularweight heparin, and warfarin have been used for pharmacological prophylaxis, heparin is the only one used perioperatively in patients undergoing neurosurgery. Heparin is a naturally occurring anticoagulant that is synthesized and secreted by mast cells in the body. It binds to antithrombin III and inhibits thrombogenesis, primarily through inactivation of factors IIa and Xa. Larger heparin fragments can also bind to and inactivate thrombin.

The low-molecular-weight heparins are fragments of unfractionated heparin with a shorter glycosaminoglycan chain length. This prevents them from binding to protein, such as thrombin. Factor $\mathrm{Xa}$ is preferentially inhibited compared with unfractionated heparin, and because thrombin is unaffected the partial thromboplastin time is normal. Theoretical advantages of low-molecular-weight heparins are more predictable anticoagulant response, greater bioavailability and longer halflife when administered subcutaneously, lower incidence of heparin-induced thrombocytopenia, and less inhibition of platelet function. ${ }^{40}$

It is unclear when to start prophylaxis and how long to continue it. Some practitioners advocate 2 weeks of prophylaxis for all patients after surgery. They support this recommendation with studies indicating that the majority of acute clinically apparent DVTs are diagnosed during this time period, and it is also the time in which $75 \%$ of asymptomatic DVTs are believed to be formed. ${ }^{24}$ Others propose a longer duration of prophylaxis, observing that patients who remained at risk for DVT after 1 or 2 weeks experienced this condition at the same rate as control patients after mechanical prophylaxis was stopped. Macdonald, et al., ${ }^{41}$ reported that in $50 \%$ of patients in whom DVT developed, it occurred between 1 and 2 months postsurgery.

Whether heparin should be started intraoperatively or at some early point postsurgery has not been determined. Given that bleeding after craniotomy may result in devastating complications, many practitioners wait at least 1 day after surgery to begin heparin administration. ${ }^{21}$ Waiting to begin heparin treatment until the early postoperative period does not appear to increase the rate of DVT formation. Macdonald, et al., studied patients in the initial days after surgery and did not detect a single DVT in more than 100 patients examined using Doppler ultrasonography within 2 or 3 days of the procedure.

\section{Comparison of Prophylactic Strategies}

Comparing studies of venous thromboembolism prophylaxis is difficult for several reasons: 1) the studies vary in the method used to diagnose venous thromboembolism; 2 ) there is marked variability in the types of patients studied; and 3) the number of patients in the studies is often small, making it difficult to perform any reliable statistical analysis on the results. ${ }^{67}$

In 1986, the participants in the National Institutes of Health Consensus Conference recommended mechanical DVT prophylaxis methods for patients undergoing craniotomy for tumor, subarachnoid hemorrhage, arteriovenous malformations, shunt placement, and other intracranial procedures. They recommended pharmacological prophylaxis only in patients undergoing extracranial procedures. $^{4}$

Although investigators in a study in which leg venography with contrast enhancement was used found that patients receiving prophylaxis only with compression stockings had a DVT rate of $32 \%,{ }^{2}$ most other researchers have reported much lower rates. Intermittent pneumatic compression has been shown to be effective in reducing the incidence of DVT from 23 to $6 \%$, a risk reduction of $74 \%$. The apparent incidence of DVT is lower when screening is performed using radioactive fibrinogen scanning. ${ }^{1}$ In one metaanalysis, intermittent pneumatic compression was found to provide a $63 \%$ risk reduction for DVT and a $49 \%$ risk reduction for PE. ${ }^{67}$ Perhaps the most important incidences of thromboembolism are those associated with clinically diagnosed DVT and PE. In Table 3 we summarize the incidence of DVT and PE among patients receiving mechanical prophylaxis compared with those who receive no preventive treatment.

Graduated knee-high or thigh-high compression stockings have been reported by some investigators to be as effective as intermittent pneumatic compression in preventing DVT. ${ }^{66,67}$ There are studies in which intermittent pneumatic compression has been applied only to one leg, with the other being used as a control. In the treated leg there was a $3 \%$ incidence of DVT, whereas its incidence in the control leg was $24 \% .{ }^{67}$ The investigators concluded

TABLE 3

Studies showing risk of thromboembolism with mechanical prophylaxis alone postcraniotomy*

\begin{tabular}{lllcl}
\hline \hline & & \multicolumn{2}{c}{$\begin{array}{c}\text { Weighted Mean }(\%) \\
\text { for Complication }\end{array}$} & \\
\cline { 3 - 4 } Prophylaxis & $\begin{array}{c}\text { Reference } \\
\text { Pop (no.) }\end{array}$ & DVT & PE & References \\
\hline none & 2670 & 4.3 & $1.40 \dagger$ & $13,14,18,23,54,72$ \\
mechanical & 2949 & 1.42 & 0.68 & $\begin{array}{l}7,11,12,22,24,25, \\
41,48,54,61,64, \\
\end{array}$ \\
& & & & 66,73 \\
\hline
\end{tabular}

$*$ Pop = population.

$\uparrow$ Not all of the studies in this subgroup specified the incidence of PE. 
that intermittent compression of one leg was not protective against DVT in the other one.

Mechanical prophylaxis provides a well-documented benefit in the prevention of DVT, and at most only theoretical risks of fibrinolysis and clot dislodgement. ${ }^{17}$ It is widely accepted that every patient should receive some form of mechanical prophylaxis. There are some advantages to compression stockings, such as ease of application and better patient compliance. Nevertheless, there is inadequate information to determine whether stockings are as effective as pneumatic compression boots. In 2001, Cupitt ${ }^{21}$ reported that $90 \%$ of neurosurgical units used graduated compression stockings instead of intermittent pneumatic compression devices. Mechanical techniques offer adequate prophylaxis for low- and moderaterisk patients, but may be suboptimal with higher-risk individuals. ${ }^{33}$

Cerrato, et al., ${ }^{14}$ randomized 100 craniotomy patients to a control group and a heparin recipient group and found that heparin decreased the rate of DVT detected using radiolabeled fibrinogen to $6 \%$, compared with $34 \%$ in the control group. In this and most other trials discussed in the present study, the control group received mechanical prophylaxis only. Macdonald and colleagues ${ }^{41}$ conducted a study in which perioperative subcutaneous heparin was used in 106 patients; these authors stated that heparin may be safe to administer to patients undergoing craniotomy, but that a larger study was needed to demonstrate efficacy. Constantini, et al., ${ }^{18}$ reported that the incidence of clinically evident DVT was 2.3 to $19 \%$, with a $3.9 \%$ incidence of PE. In addition, they concluded that minidoses of unfractionated heparin were safe to use in the perioperative period. Wen and Hall, ${ }^{70}$ in a series of 152 patients undergoing cranial procedures who were treated with twicedaily minidoses of heparin starting before surgery, observed only two episodes of major bleeding and concluded that this regimen was safe. In a recent review, Misra and associates ${ }^{43}$ examined more than 1000 neurosurgery intensive care unit admissions and found a 3\% incidence of DVT on follow-up studies, and a $0.1 \%$ risk of PE. They concluded that a regimen of twice-weekly ultrasound scanning combined with low-dose unfractionated heparin was effective. Nevertheless, they failed to specify when prophylaxis was started or to stratify patients by diagnosis.

Because of the theoretical risk of hemorrhagic complications after therapy with unfractionated heparin, the use of low-molecular-weight heparins, which have less of an effect on antithrombin III and so maintain an antithrombotic effect with a limited anticoagulation effect, has been suggested for high-risk patients. ${ }^{29,48}$

In a prospective trial conducted by Goldhaber, et al., ${ }^{29}$ 150 patients were assigned to groups receiving mechanical prophylaxis and either unfractionated heparin or enoxaparin. These authors found a $24 \%$ risk of DVT with enoxaparin and $13 \%$ with heparin. They concluded that enoxaparin did not demonstrate superior efficacy in preventing DVT or PE when compared to heparin. In a multicenter trial, ${ }^{48} 485$ patients were randomly allocated to receive either nadroparin, a low-molecular-weight heparin, or graduated compression stockings. The relative short-term risk reduction for DVT in the treatment group was $28.9 \%$. The investigators reported an insignificant trend toward increased major bleeding and mortality rates, but concluded that the benefit of using pharmacological prophylaxis outweighed the risks. In a smaller study of patients with brain tumors, enoxaparin treatment initiated at the time of surgery increased the risk of $\mathrm{ICH}$, and the study was terminated early. ${ }^{22}$ Agnelli and associates ${ }^{2}$ randomized 307 patients and found that enoxaparin started the morning after surgery significantly reduced the risk of DVT without significantly increasing the risk of intracranial bleeding. Norwood, et al., ${ }^{47}$ evaluated the safety of enoxaparin prophylaxis in 150 patients with intracranial hemorrhagic injuries and concluded that this drug could be safely used when it was started 24 hours after admission or craniotomy.

Macdonald, et al., ${ }^{40}$ studied dalteparin, a low-molecular-weight heparin, comparing it with unfractionated heparin in a randomized trial of 100 patients. They found a $0 \%$ rate of DVT in the group treated with heparin, and a $2 \%$ risk of DVT in those treated with dalteparin. They concluded that both interventions were safe for prophylaxis. In a retrospective review of 150 patients in whom certoparin was used, the risk of DVT and PE was 0.2 and $0.1 \%$, respectively. ${ }^{38}$ Table 4 summarizes the risk of DVT and PE when mechanical and pharmacological prophylaxis were combined.

\section{Risk of ICH With Pharmacological Prophylaxis}

Because of an understandable fear of complications from anticoagulation therapy, there remains a reluctance to use routine pharmacological prophylaxis. Stephens, et al., ${ }^{62}$ in a survey of 44 British neurosurgical units, found that only $32 \%$ used pharmacological prophylaxis perioperatively, and that this rate is reduced to $6 \%$ in units in which emergency neurosurgery is performed. ${ }^{56}$ The need for repeated intervention because of bleeding complications has been estimated to vary between 1 and $8 \% .{ }^{35}$

Both unfractionated and low-molecular-weight heparin have been subject to scrutiny. Wen and Hall ${ }^{70}$ performed an analysis of the literature and found a hematoma rate of $1.2 \%$ in patients given unfractionated heparin, and a rate of $1.6 \%$ in those not treated in a total of 2400 patients. In a review of more than 1500 patients who underwent craniotomy and then received mechanical prophylaxis and low-molecular-weight heparin, Raabe, et al. ${ }^{52}$ observed a

TABLE 4

Studies showing risk of thromboembolism with mechanical plus pharmacological prophylaxis postcraniotomy*

\begin{tabular}{ccccc}
\hline \hline \multicolumn{1}{c}{ Prophylaxis } & $\begin{array}{c}\text { Reference } \\
\text { Pop (no.) }\end{array}$ & $\begin{array}{c}\text { Weighted Mean (\%) } \\
\text { for Complication }\end{array}$ & \\
\cline { 3 - 4 } $\begin{array}{c}\text { PC }+ \\
\text { unfractionated heparin }\end{array}$ & 3550 & 1.83 & 0.34 & $\begin{array}{c}15,25,29,40, \\
41,52\end{array}$ \\
$\begin{array}{c}\text { PC }+ \\
\text { low-molecular-weight } \\
\text { heparin }\end{array}$ & 2004 & 0.50 & 0.15 & $\begin{array}{c}3,22,29,38, \\
40,48\end{array}$ \\
\hline
\end{tabular}

* $\mathrm{PC}=$ pneumatic compression. 
$2 \%$ risk of hemorrhage requiring intervention. Paoletti, et al., ${ }^{50}$ treated 917 patients with fraxiparin, a low-molecularweight heparin, and noted 19 postoperative hematomas, none of which required surgical evacuation. The risk of intracranial bleeding from nadroparin was found to be higher compared with enoxaparin; $2.5 \%$ compared with $0.4 \% .^{2,48}$

In the largest series of craniotomies to date in which perioperative low-molecular-weight heparin was used for prophylaxis, a hemorrhage rate of more than $3 \%$ was observed; nevertheless, the authors concluded that the data supported its use..$^{28}$ The risk of hemorrhage with and without heparin prophylaxis is summarized in Table 5. The sequelae of postoperative ICHs are bleak; on average more than $35 \%$ of patients are left with severe neurological deficits and $25 \%$ die. . $^{2,9,13,18,23,26,27,36,48,49,54,63,64,72}$

\section{CONCLUSIONS}

Unfortunately, the literature provides little guidance on the most effective and safest means to prevent thromboembolic complications in patients who undergo craniotomy. Most investigators have concentrated on the incidence of DVT, as measured in follow-up studies. This approach fails to determine, however, whether DVTs discovered during follow-up examinations have the same impact as lesions that are associated with clinical findings such as leg swelling or pain. It also fails to consider the offsetting risks of ICH, the occurrence of which is bound to rise as heparin reduces the risk of DVT.

One might argue that a randomized, controlled clinical trial or metaanalysis in which two or all three treatment options are compared would provide Class I evidence. Indeed, such a trial has been suggested. ${ }^{30,41,52,69}$ Several small controlled trials have been performed, ${ }^{2,8,14,29,40,42,48}$ as was a metaanalysis of some of their results. ${ }^{35}$ We must emphasize, however, that no conclusion could be reached as to which approach led to the best outcomes. Nor is it obvious how outcome would be defined in a clinical trial balancing competing risks, such as thromboembolism and ICH. Furthermore, the size of such a trial would be immense. Using the data discussed here, one can estimate the size of a suitably powered clinical trial that would be needed to demonstrate a significant difference between pneumatic compression alone and unfractionated heparin with regard to the occurrence and results of serious complications. If current incidences hold, such a trial would

TABLE 5

Studies showing risk of $\mathrm{ICH}$

with DVT prophylaxis postcraniotomy

\begin{tabular}{lccc}
\hline \hline \multicolumn{1}{c}{ Prophylaxis } & $\begin{array}{c}\text { Reference } \\
\text { Pop (no.) }\end{array}$ & $\begin{array}{c}\text { Weighted } \\
\text { Mean (\%) }\end{array}$ & References \\
\hline PC only & 31,725 & 1.11 & $\begin{array}{c}3,6,13,14,18,22,23, \\
25-27,34,36,41,48,\end{array}$ \\
& & & $49,54,63,64,68,72$ \\
& & & $5,8,14,18,25,29,40$, \\
PC + & 1,922 & 1.87 & $41,52,70$ \\
$\quad$ unfractionated heparin & & & $3,22,29,38,40,48$ \\
PC + & 2,025 & 3.16 & \\
$\begin{array}{l}\text { low-molecular-weight } \\
\text { heparin }\end{array}$ & & & \\
\hline
\end{tabular}

require more than 38,000 subjects. Such a two-armed trial would be too large to be practical, to say nothing of a trial in which all three treatment options could be compared.

We are currently preparing a threshold analysis to assist individual surgeons and institutions in decisions about prophylactic measures in their patients who undergo craniotomy. Depending on the observed incidence of DVT, $\mathrm{PE}$, and postoperative hemorrhage, the analysis can be used to predict whether the overall outcome will be better if heparin is added to pneumatic compression.

\section{References}

1. Agnelli G: Prevention of venous thromboembolism after neurosurgery. Thromb Haemost 82:925-930, 1999

2. Agnelli G, Piovella F, Buoncristiani P, et al: Enoxaparin plus compression stockings compared with compression stockings alone in the prevention of venous thromboembolism after elective neurosurgery. N Engl J Med 339:80-85, 1998

3. Anderson FA Jr, Wheeler HB, Goldberg RJ, et al: A populationbased perspective of the hospital incidence and case-fatality rates of deep vein thrombosis and pulmonary embolism. The Worcester DVT Study. Arch Intern Med 151:933-938, 1991

4. Anonymous: Prevention of venous thrombosis and pulmonary embolism. NIH Consensus Development. JAMA 256: 744-749, 1986

5. Barnett HG, Clifford JR, Llewellyn RC: Safety of mini-dose heparin administration for neurosurgical patients. J Neurosurg 47:27-30, 1977

6. Basali A, Mascha EJ, Kalfas I, et al: Relation between perioperative hypertension and intracranial hemorrhage after craniotomy. Anesthesiology 93:48-54, 2000

7. Black PM, Baker MF, Snook CP: Experience with external pneumatic calf compression in neurology and neurosurgery. Neurosurgery 18:440-444, 1986

8. Bostrom S, Holmgren E, Jonsson O, et al: Post-operative thromboembolism in neurosurgery. A study on the prophylactic effect of calf muscle stimulation plus dextran compared to low-dose heparin. Acta Neurochir 80:83-89, 1986

9. Brisman $\mathrm{MH}$, Bederson JB, Sen $\mathrm{CN}$, et al: Intracerebral hemorrhage occurring remote from the craniotomy site. Neurosurgery 39:1114-1122, 1996

10. Browse NL, Jackson BT, Mayo ME, et al: The value of mechanical methods of preventing postoperative calf vein thrombosis. Br J Surg 61:219-223, 1974

11. Bucci MN, Papadopoulos SM, Chen JC, et al: Mechanical prophylaxis of venous thrombosis in patients undergoing craniotomy: a randomized trial. Surg Neurol 32:285-288, 1989

12. Bynke O, Hillman J, Lassvik C: Does peroperative external pneumatic leg muscle compression prevent post-operative venous thrombosis in neurosurgery? Acta Neurochir 88:46-48, 1987

13. Cabantog AM, Bernstein M: Complications of first craniotomy for intra-axial brain tumor. Can J Neurol Sci 21:213-218, 1994

14. Cerrato D, Ariano C, Fiacchino F: Deep vein thrombosis and low-dose heparin prophylaxis in neurosurgical patients. J Neurosurg 49:378-381, 1978

15. Chan AT, Atiemo A, Diran LK, et al: Venous thromboembolism occurs frequently in patients undergoing brain tumor surgery despite prophylaxis. J Thromb Thrombolysis 8:139-142, 1999

16. Cheruku R, Tapazoglou E, Ensley J, et al: The incidence and significance of thromboembolic complications in patients with high-grade gliomas. Cancer 68:2621-2624, 1991

17. Comerota AJ, Chouhan V, Harada RN, et al: The fibrinolytic effects of intermittent pneumatic compression: mechanism of enhanced fibrinolysis. Ann Surg 226:306-314, 1997 
18. Constantini S, Kanner A, Friedman A, et al: Safety of perioperative minidose heparin in patients undergoing brain tumor surgery: a prospective, randomized, double-blind study. J Neurosurg 94:918-921, 2001

19. Constantini S, Kornowski R, Pomeranz S, et al: Thromboembolic phenomena in neurosurgical patients operated upon for primary and metastatic brain tumors. Acta Neurochir 109: 93-97, 1991

20. Coon WW: Venous thromboembolism. Prevalence, risk factors, and prevention. Clin Chest Med 5:391-401, 1984

21. Cupitt JM: Prophylaxis against thromboembolism in patients with traumatic brain injury: a survey of UK practice. Anaesthesia 56:780-785, 2001

22. Dickinson LD, Miller LD, Patel CP, et al: Enoxaparin increases the incidence of postoperative intracranial hemorrhage when initiated preoperatively for deep venous thrombosis prophylaxis in patients with brain tumors. Neurosurgery 43:1074-1081, 1998

23. Fadul C, Wood J, Thaler H, et al: Morbidity and mortality of craniotomy for excision of supratentorial gliomas. Neurology 38:1374-1379, 1988

24. Flinn WR, Sandager GP, Silva MB Jr, et al: Prospective surveillance for perioperative venous thrombosis. Experience in 2643 patients. Arch Surg 131:472-480, 1996

25. Frim DM, Barker FG II, Poletti CE, et al: Postoperative lowdose heparin decreases thromboembolic complications in neurosurgical patients. Neurosurgery 30:830-833, 1992

26. Fukamachi A, Koizumi H, Nagaseki Y, et al: Postoperative extradural hematomas: computed tomographic survey of 1105 intracranial operations. Neurosurgery 19:589-593, 1986

27. Fukamachi A, Koizumi H, Nukui H: Postoperative intracerebral hemorrhages: a survey of computed tomographic findings after 1074 intracranial operations. Surg Neurol 23:575-580, 1985

28. Gerlach R, Scheuer T, Beck J, et al: Risk of postoperative hemorrhage after intracranial surgery after early nadroparin administration: results of a prospective study. Neurosurgery 53: 1028-1035, 2003

29. Goldhaber SZ, Dunn K, Gerhard-Herman M, et al: Low rate of venous thromboembolism after craniotomy for brain tumor using multimodality prophylaxis. Chest 122:1933-1937, 2002

30. Guidry U, McLaren Black P, Goldhaber SZ: Venous thromboembolism prophylaxis in the craniotomy patient: an editorial. Surg Neurol 50:182-183, 1998

31. Hamilton MG, Hull RD, Pineo GF: Prophylaxis of venous thromboembolism in brain tumor patients. J Neurooncol 22: 111-126, 1994

32. Hamilton MG, Hull RD, Pineo GF: Venous thromboembolism in neurosurgery and neurology patients: a review. Neurosurgery 34:280-296, 1994

33. Huisman MV, Buller HR, ten Cate JW, et al: Serial impedance plethysmography for suspected deep venous thrombosis in outpatients. The Amsterdam General Practitioner Study. N Engl J Med 314:823-828, 1986

34. Hussain SA, Selway R, Harding C, et al: The urgent postoperative CT scan: a critical appraisal of its impact. Br J Neurosurg 15:116-118, 2001

35. Iorio A, Agnelli G: Low-molecular-weight and unfractionated heparin for prevention of venous thromboembolism in neurosurgery: a meta-analysis. Arch Intern Med 160:2327-2332, 2000

36. Kalfas IH, Little JR: Postoperative hemorrhage: a survey of 4992 intracranial procedures. Neurosurgery 23:343-347, 1988

37. Kamran SI, Downey D, Ruff RL: Pneumatic sequential compression reduces the risk of deep vein thrombosis in stroke patients. Neurology 50:1683-1688, 1998

38. Kleindienst A, Harvey HB, Mater E, et al: Early antithrombotic prophylaxis with low molecular weight heparin in neurosurgery. Acta Neurochir 145:1085-1091, 2003

39. Levi AD, Wallace MC, Bernstein M, et al: Venous thromboem- bolism after brain tumor surgery: a retrospective review. Neurosurgery 28:859-863, 1991

40. Macdonald RL, Amidei C, Baron J, et al: Randomized, pilot study of intermittent pneumatic compression devices plus dalteparin versus intermittent pneumatic compression devices plus heparin for prevention of venous thromboembolism in patients undergoing craniotomy. Surg Neurol 59:363-374, 2003

41. Macdonald RL, Amidei C, Lin G, et al: Safety of perioperative subcutaneous heparin for prophylaxis of venous thromboembolism in patients undergoing craniotomy. Neurosurgery 45: 245-252, 1999

42. Melon E, Keravel Y, Gaston A, et al: Deep venous thrombosis prophylaxis by low molecular weight heparin in neurosurgical patients. Anesthesiology 75 (Suppl 1):A214, 1991 (Abstract)

43. Misra M, Roitberg B, Ebersole K, et al: Prevention of pulmonary embolism by combined modalities of thromboprophylaxis and intensive surveillance protocol. Neurosurgery 54: 1099-1103, 2004

44. Missori P, Lunardi P, Salvati M, et al: Pulmonary embolism in neurosurgical patients. Neurochirurgia 34:170-173, 1991

45. Muchmore JH, Dunlap JN, Culicchia F, et al: Deep vein thrombophlebitis and pulmonary embolism in patients with malignant gliomas. South Med J 82:1352-1356, 1989

46. Myllynen P, Kammonen M, Rokkanen P, et al: Deep venous thrombosis and pulmonary embolism in patients with acute spinal cord injury: a comparison with nonparalyzed patients immobilized due to spinal fractures. J Trauma 25:541-543, 1985

47. Norwood SH, McAuley CE, Berne JD, et al: Prospective evaluation of the safety of enoxaparin prophylaxis for venous thromboembolism in patients with intracranial hemorrhagic injuries. Arch Surg 137:696-702, 2002

48. Nurmohamed MT, van Riel AM, Henkens CM, et al: Low molecular weight heparin and compression stockings in the prevention of venous thromboembolism in neurosurgery. Thromb Haemost 75:233-238, 1996

49. Palmer JD, Sparrow OC, Iannotti F: Postoperative hematoma: a 5-year survey and identification of avoidable risk factors. Neurosurgery 35:1061-1065, 1994

50. Paoletti C, Maubec E, Raggueneau JL, et al: [Clinical tolerance of CY 216 (Fraxiparin) in the prevention of thromboembolic accidents after neurosurgery.] Agressologie 30:363-366, 1989 (Fre)

51. Quevedo JF, Buckner JC, Schmidt JL, et al: Thromboembolism in patients with high-grade glioma. Mayo Clin Proc 69: 329-332, 1994

52. Raabe A, Gerlach R, Zimmermann M, et al: The risk of haemorrhage associated with early postoperative heparin administration after intracranial surgery. Acta Neurochir 143:1-7, 2001

53. Rossi R, Agnelli G, Taborelli P, et al: Local versus central assessment of venographies in a multicenter trial on the prevention of deep vein thrombosis in neurosurgery. Thromb Haemost 82:1399-1402, 1999

54. Ruff RL, Posner JB: Incidence and treatment of peripheral venous thrombosis in patients with glioma. Ann Neurol 13: 334-336, 1983

55. Sawaya R, Cummins CJ, Kornblith PL: Brain tumors and plasmin inhibitors. Neurosurgery 15:795-800, 1984

56. Sawaya R, Decourteen-Meyers G, Copeland B: Massive preoperative pulmonary embolism and suprasellar brain tumor: case report and review of the literature. Neurosurgery 15:566-571, 1984

57. Sawaya R, Kornblith PL: Brain tumors and thromboembolic complications. Surg Neurol 28:163, 1987

58. Sawaya R, Zuccarello M, Elkalliny M, et al: Postoperative venous thromboembolism and brain tumors: Part I. Clinical profile. J Neurooncol 14:119-125, 1992

59. Sawaya RE, Ligon BL: Thromboembolic complications associated with brain tumors. J Neurooncol 22:173-181, 1994

60. Scmidt EV, Smirnov VE, Ryabova VS: Results of the seven- 


\section{S. F. Danish, M. G. Burnett, and S. C. Stein}

year prospective study of stroke patients. Stroke 19:942-949, 1988

61. Skillman JJ, Collins RE, Coe NP, et al: Prevention of deep vein thrombosis in neurosurgical patients: a controlled, randomized trial of external pneumatic compression boots. Surgery 83: 354-358, 1978

62. Stephens PH, Healy MT, Smith M, et al: Prophylaxis against thromboembolism in neurosurgical patients: a survey of current practice in the United Kingdom. Br J Neurosurg 9:159-163, 1995

63. Taylor WA, Thomas NW, Wellings JA, et al: Timing of postoperative intracranial hematoma development and implications for the best use of neurosurgical intensive care. J Neurosurg 82:48-50, 1995

64. Ting AC, Cheng SW, Cheung GC, et al: Perioperative deep vein thrombosis in Chinese patients undergoing craniotomy. Surg Neurol 58:274-279, 2002

65. Tomita T, Raimondi AJ: Brain tumors in the elderly. JAMA 246:53-55, 1981

66. Turpie AG, Hirsh J, Gent M, et al: Prevention of deep vein thrombosis in potential neurosurgical patients. A randomized trial comparing graduated compression stockings alone or graduated compression stockings plus intermittent pneumatic compression with control. Arch Intern Med 149:679-681, 1989

67. Vanek VW: Meta-analysis of effectiveness of intermittent pneumatic compression devices with a comparison of thighhigh to knee-high sleeves. Am Surg 64:1050-1058, 1998
68. Vassilouthis J, Anagnostaras S, Papandreou A, et al: Is postoperative haematoma an avoidable complication of intracranial surgery? Br J Neurosurg 13:154-157, 1999

69. Walsh DC, Kakkar AK: Thromboembolism in brain tumors. Curr Opin Pulm Med 7:326-331, 2001

70. Wen DY, Hall WA: Complications of subcutaneous low-dose heparin therapy in neurosurgical patients. Surg Neurol 50: 521-525, 1998

71. White RH, McGahan JP, Daschbach MM, et al: Diagnosis of deep-vein thrombosis using duplex ultrasound. Ann Intern Med 111:297-304, 1989

72. Wilson CB: General considerations, in Apuzzo MLJ (ed): Brain Surgery: Complication Avoidance and Management. New York: Churchill Livingstone, 1993, Vol 1, pp 177-185

73. Zelikovski A, Zucker G, Eliashiv A, et al: A new sequential pneumatic device for the prevention of deep vein thrombosis. J Neurosurg 54:652-654, 1981

Manuscript received June 15, 2004

Accepted in final form September 7, 2004.

Address reprint requests to: Shabbar F. Danish, M.D., Department of Neurosurgery, Hospital of the University of Pennsylvania, Silverstein Building 3rd Floor, 3400 Spruce Street, Philadelphia, Pennsylvania 19104. email: Shabbardanish@hotmail.com. 